\title{
The Case for Ongoing Student Course Assessment
}

\author{
Abi Aghayere \\ College of Applied Science and Technology (CAST) \\ Rochester Institute of Technology
}

\begin{abstract}
Most colleges in the United States use end-of-term course assessment as the main feedback mechanism from students. By using this method of summative assessment, students are able to rate the course, the performance of the instructor, and what they have learned in the course, among other things. One drawback of the end-of-term feedback is that the current students are not able to benefit from any improvements in the course that may result from their feedback.

To overcome this drawback, the author explores in this paper the use of ongoing assessment of student understanding of course topics throughout the quarter using module surveys. In this paper, the author presents the advantages of the ongoing assessment technique, the survey data from online and on-campus sections of the author's structural analysis course, and feedback from students regarding the effectiveness of the module surveys. This continuous improvement process has been successfully adopted in the author's structural analysis, structural steel design and reinforced concrete design courses. The analysis of the data obtained from administering this survey to students in the structural analysis course is presented. Based on the survey data and the students' feedback, it can be concluded that ongoing formative assessment methods enhance student learning and should be adopted in Engineering Technology (ET) courses as one way of satisfying the "closed loop" continuous improvement process now required by the accrediting agencies.
\end{abstract}

\section{Introduction}

Many institutions in the United States use some form of summative evaluation at the end of the term for the courses they offer. Through use of the end-of-term surveys, students rate the instructor, the course delivery method, the text book and other aspects of the course, but they do not benefit from any improvements or modifications to the course that may result from their feedback because these surveys are administered to the students toward the end of the term. Moreover, the instructor is not likely to easily and quickly identify students who may be struggling in the course until the student fails an exam, by which time it may be too late. This is an obvious drawback of the summative evaluation approach.

The author is not aware of any ET program that uses ongoing assessment of topic-specific intended learning outcomes to obtain immediate student feedback that can benefit current students. ${ }^{1}$ This may be due partly to the amount of resources and time required to carry out these surveys and analyze the data obtained. The author has previously used this continuous and ongoing assessment technique to compare student learning in a face-to-face on-campus class and an online distance class, ${ }^{1}$ finding no significant differences in student learning. Nancy Hunt ${ }^{2}$ carried out mid-semester surveys and reported positive impact on student learning. Morgan and

Proceedings of the 2005 American Society for Engineering Education Annual Conference \& Exposition Copyright (C) 2005, American Society for Engineering Education 
Tallman $^{3}$ carried out assessment of broad course learning outcomes using student surveys, but these surveys were episodic rather than ongoing. They were administered to students towards the end of the term and the learning outcomes were rather broad and not broken down into specific course topics.

In this era of continuous improvement now mandated by accrediting agencies like the Accreditation Board for Engineering and Technology (ABET) and Middle States, many programs and departments are beginning to reassess the way their courses are evaluated. ${ }^{1,4}$ To ensure continuous improvement in courses that benefits current students, the author believes that course evaluations should be geared more towards improving the course and enhancing student learning. To achieve this goal, the author proposes the use of ongoing formative evaluation methods that measures student understanding of course-specific topics in addition to the end-ofterm summative evaluations. In this paper, the author presents the formative assessment instrument used, the survey results and impact on student learning in the online and oncampus structural analysis courses, and students' perception on the effectiveness of these surveys. The analysis of the survey data and the student feedback shows that ongoing assessment of intended learning outcomes does enhance student learning. The use of this ongoing assessment enriches and deepens student learning and provides ET faculty and programs with a "closed loop" mechanism for continuous improvement that meets the requirements of accrediting agencies.

\section{Assessment Methods}

There are different assessment methods available in the literature for measuring student learning. 1, 4, 5, 6,7 These can be divided into direct (or formal) and indirect assessment methods. Direct assessments include tests, design projects, papers, theses, and written exams. Indirect assessments include self-report surveys at the course, program or institutional levels. These assessment methods can be further divided into formative (during the term) or summative (end of term) evaluations. ${ }^{4,6}$ According to Wankat and Oreovicz " "formative evaluations are obviously more useful for course improvement than summative evaluations - the course is still in session and there is time for improvement." It is also important that assessments be carried out at the individual student level otherwise the effectiveness of assessment diminishes considerably. ${ }^{10}$

In this paper, the author adopts a formative classroom assessment technique ${ }^{8,9}$ which involves ongoing assessment of student understanding of very specific learning outcomes. The assessment is carried out at the individual student level, and the outcomes developed for the course were designed to be a very specific checklist of all the topics covered in the course. This assessment technique helps the students and the instructor to recognize areas of weaknesses in the students' understanding and helps the instructor "fill in any knowledge gap that can keep a student from progressing." The assessment instrument was administered to students in the fall 2004 structural analysis course. A total of 50 students were registered for this course with 39 students in the oncampus section and 11 in the online section.

The ongoing assessment procedure used in this study involves the development of eight modules for the course with each module having a set of topic-specific intended learning outcomes (ILOs). The students are asked to rate their level of understanding of these course topics or ILOs on a scale of 1 (not understood at all) through 5 (very well understood). In addition, they are 
required for (each module) to describe briefly what was most meaningful to them with regards to what they learned in that module and what was unclear. A sample of the module assessment instruments used in the structural analysis course are shown in the appendix. The module ratings are used by the instructor to assess student learning on an ongoing basis and to make any necessary mid-stream corrections to the course delivery method or courses notes, to identify struggling students who may be in need of extra tutoring sessions, and to identify problem topic areas that may need to be revisited in class. If a relative few number of students indicate module ratings of 2 or less on any of the ILOs, these students are usually invited to meet with the instructor for extra tutoring. To gauge the effectiveness of the module surveys from the students' perspective, they were also asked to answer two additional open-ended questions on the last module (Module 8).

\section{Assessing Student Learning}

The structural analysis course is a 4 credit course offered in the fall quarter. The on-campus section meets for 50 minutes four times a week for ten weeks. The online section of the course, instructor-to-student and student-to-student interactions take place on the course website. The course was divided into eight modules, each with its intended learning outcomes (ILOs) that was used to measure student understanding of every topic in the course. Modules 1 through 7 were used to assess the student understanding of course topics while Module 8 was used to assess student understanding of the overall course objectives. The data obtained from the module surveys was analyzed using a spreadsheet program. Table 1 shows a summary of the assessment results for each module from the fall 2004 structural analysis class with the mean and the most frequent ratings. Analysis of the survey data results in a mean value of approximately 4.0 for the module ratings and a modal or most frequent response of 4 , indicating that student learning was achieved in this course. The results did not indicate any significant differences or variations across learning outcomes, thus pointing to consistency in the delivery method for this course.

The average module rating for the course was 4.03 and the overall grade point average in the course was 2.45 or a $\mathrm{C}+$ grade point average. The correlation coefficient $r$ between the average module rating and the course grade for each student was calculated as +0.50 . This indicates a positive correlation between the indirect assessment method used in this course as measured by the course module ratings and the direct assessment method used as measured by the final course grade obtained by the students. The correlation coefficient calculated implies that a higher module rating by a student translates into a higher course grade, and vice versa.

The overall average for this course was found to be $75.3 \%$ for the fall 2004 session. As a comparison, the overall average for the previous four offerings of this course was $72.7 \%$, thus indicating a slight improvement in performance as a result of the intervention though the difference is not statistically significant. More studies are underway to ascertain if there is a direct correlation between the module ratings and student performance in structural design and other courses in the civil engineering technology program. It appears that student retention in the course was also improved as a result of this intervention. The course started out with 51 students (40 on-campus and 11 online) with only one student dropping the course, indicating a 98\% retention rate. To evaluate the effectiveness of the ongoing module survey, students were 
required to answer two additional open-ended questions on module 8 . Their responses are discussed in the next section.

Table 1: Summary of Assessment Results for each Module

\begin{tabular}{|c|c|c|}
\hline Module & Mean Rating & Mode \\
\hline $\mathbf{1}$ & 4.12 & 4 \\
\hline $\mathbf{2}$ & 3.96 & 4 \\
\hline $\mathbf{3}$ & 4.0 & 4 \\
\hline $\mathbf{4}$ & 3.91 & 4 \\
\hline $\mathbf{5}$ & 4.10 & 4 \\
\hline $\mathbf{6}$ & 3.94 & 4 \\
\hline $\mathbf{7}$ & 4.06 & 4 \\
\hline $\mathbf{8}$ & 4.0 & 4 \\
\hline
\end{tabular}

Student Feedback on the Impact of the Module Surveys

To gauge the impact of the module surveys on student learning from the students' perspective, the students were asked to answer the following two additional open-ended questions which were to be submitted with the last module: How well did you reflect on the course topics (or intended learning outcomes) in the course modules before completing the module survey? How did the module survey impact your learning in this course? Here are representative samples of student responses:

"It was a good tool at going over the important points in my head and holding me accountable to learn them. I've gone back a couple of times to refresh my learning on a couple of things I was unsure off"

"It gave me a sense of what I know and didn't know and forced me to go back to something I didn't know."

"The modules made it more clear to me what I needed to study. Helped me study more of the specific things before a test."

"Modules have helped me look at what was expected of me and in turn helped to reinforce my understanding of the material. I understand all the material very well so I didn't need any assistance. However this is an excellent tool to help those students who do in fact need help understanding the concepts."

"I believe the modules really helped me to see what areas of the course I was having trouble with. Sometimes, I never knew I didn't get something until I read the module. The modules helped me to see what areas I needed to study more or seek help with." 
"I have reflected good on my modules. I filled out exactly how I felt on each topic (ILO). It has helped me learn more, because I would look at the modules and if I didn't know something on the module, I would make sure to learn it before the test."

"I was honest and accurate. [The modules] made me feel like there was a safety net in case I didn't understand something, I could personally let the professor know."

"I've been honest; the modules are a good tool to reflect on how much I've learned. It helped me prepare myself for the test."

"The modules have made me look back and make sure I understand certain concepts before the exam, which was helpful. The impact of the modules was [that] they gave me an idea [of] what concepts I should be getting out of each chapter or section."

"I feel the module [ratings] are a fairly accurate representation of my learning. The modules gave a point-by-point checklist of what was important. Turning them in forced me to think about what I learned."

"I feel that indirectly, it makes you self-reflect on how you are doing in the course and sometimes, it makes me realize that I need to hit the books a bit more. Good strategy." "I didn't reflect a whole lot when filling out the modules, but they did help give me an idea of where I stood at the end of the chapter."

From the 31 responses obtained answering the last two questions, only one student admitted to not being honest when completing the module survey. Here is the student in his own words, "I was not honest in the completion of the modules. I think that shows because I pretty much failed the first three exams." More than $70 \%$ of the students indicated that their learning was positively impacted by the module or ILO surveys, and of the remaining 30\%, many indicated that the module survey forced them to reflect or think about the course topics (ILOs), which in itself is positive. Among these were also some very bright students who felt they did not need the modules to do well in the course.

In summary, the student responses to the two questions point to the effectiveness of the ongoing assessment technique adopted in this study combined with the detailed and high level of specificity of the intended learning outcomes. The ongoing assessment technique forces the students, even those who had mastered the material in class, to reflect on what they have learned and impresses on them the realization that the instructor is really interested in their learning and is available to help them achieve success in the course.

\section{Conclusion}

The author has presented a case for the use of ongoing course-level assessment of intended learning outcomes (ILOs) to enhance student learning and ensure continuous improvement in engineering technology courses. This could be used as one way to satisfy the "closed loop" continuous improvement process required by accrediting agencies. The assessment technique 
was successfully administered to students in the fall 2004 Structural Analysis class. A total of 51 students (40 in the on-campus section and 11 in the online distance section of the class) participated in the survey. Throughout the term, students were required to periodically complete surveys that measured their level of understanding of the course topics on a scale of 1 (not understood at all) through 5 (very well understood). For every module, students were also required to briefly describe what was most meaningful with regards to what they learned and what was unclear. The author used these surveys and student feedback to make any necessary mid-stream corrections to the course, like revisiting a topic in class and/or posting clarifications on the course website. In cases where only a few students recorded ratings of 2 or less on any particular ILO, these students are immediately invited via email to meet with the instructor for one-on-one tutoring sessions on that particular topic or ILO.

Using the module surveys has helped the students focus on what they need to know and what areas they may be deficient in. Their questions were more focused and there were fewer complaints about not understanding the course material. In fact, those students that did not perform as well as they expected on the tests and exams in most cases attributed their lackluster performance to test anxiety rather than a lack of understanding of the course material or inadequate course delivery. The student feedback on the two open-ended questions points to the usefulness and effectiveness of this ongoing module survey. The author plans to develop ILOs and module surveys for more courses within the Civil Engineering Technology (CET) program at Rochester Institute of Technology (RIT) with the intent of ascertaining if there are any significant variations in the mean and modal ratings for the various courses. The results will be used to adjust or modify the course delivery methods as necessary.

Analysis of the survey data indicate that student learning was achieved in this structural analysis course. The author recommends this ongoing assessment technique be adopted in ET courses in order to enhance student learning. This assessment technique also satisfies the "closed loop" continuous improvement requirements of accrediting agencies.

Bibliography

1. Abi Aghayere (2004), "Use of Ongoing Assessment of Intended Learning Outcomes to Evaluate Effectiveness of Online and Oncampus Delivery of a Structural Analysis Course," ASEE Annual Conference, Salt Lake City.

2. Nancy Hunt (2003), "Does Mid-Semester Feedback Make a Difference," The Journal of Scholarship of Teaching and Learning (JoSoTL), Vol 3, Number 2.

3. James N. Morgan and Gary D. Tallman (2002), "Development, Implementation, and assessment of Course Learning Outcomes," Working Paper Series, College of Business Administration, Northern Arizona University, Flagstaff, AZ.

4. Raghu Echempti, Arnaldo Mazzei, and Karim Nasr (2004), "Student Understanding of Program Outcomes through Formative and Summative Course-level Assessment", ASEE Annual Conference, Salt Lake City

5. Arapahoe Community College, "Assessment: An Institution-wide Process to Improve Student Academic Achievement," http://www.arapahoe.edu/aboutacc/assessment/

6. Philip Wankat and Frank Oreovicz (2004), "Necessary Evil," Teaching Tool Box, ASEE Prism, November, pg 44

7. John M. Norris (2002), "Progress in Assessing and Improving Student Learning Outcomes in Academic Units: 1999-2002," Northern Arizona University Office of Academic Assessment 
8. T.P. Angelo and K.P. Cross (1993), "Classroom Assessment Techniques: A Handbook for College Teachers," $2^{\text {nd }}$ edition, Jossey-Bass, San Francisco

9. Gwynn Mettetal (2001), "The What, Why and How of Classroom Action Research," The Journal of Scholarship of Teaching and Learning (JoSoTL), Vol 2, Number 1.

10. Alvin P. Sanoff (2005), “Measure for Measure,” ASEE Prism, January, pp. 36-40

\section{ABI AGHAYERE}

Abi Aghayere is associate professor of civil engineering technology at Rochester Institute of Technology and the Faculty Associate for Scholarship in CAST. He received a B.S. in Civil Engineering from the University of Lagos, a S.M. in Structural Engineering from MIT, and a Ph.D. in Structural Engineering from the University of Alberta. Dr. Aghayere has over 16 years consulting experience and he is a licensed engineer in Ontario, Canada. 
Appendix

STRUCTURAL ANALYSIS COURSE MODULES \& SURVEY 0608-490.01 Fall Quarter 2004

- Please rate each of the Intended Learning Outcomes (ILO's) on a scale of 1 (least understood) to 5 (very well understood) after each module is completed, by ticking the appropriate box.

Also, for EACH module, describe briefly what was most meaningful to you in terms of what you learned and what was unclear.

- Please submit your surveys to me at the end of each module.

Thank you in advance for your participation and cooperation, and for helping me to help you learn better!

0608-490- Module 1

\section{READING ASSIGNMENT:}

기llabus \& Introduction

- Review of Statics

- Course Notes (text \# 1) chapters $1 \& 2$

- Text \#2 chapters $1 \& 2$

\section{INTENDED LEARNING OUTCOMES (ILO's):}

After completing this module, you should be able to:

\begin{tabular}{|l|l|l|l|l|l|}
\hline & $\begin{array}{l}\mathbf{5}= \\
\text { Very well } \\
\text { understood }\end{array}$ & $\begin{array}{l}\mathbf{4}= \\
\text { Understood }\end{array}$ & $\begin{array}{l}\mathbf{3}= \\
\text { Somewhat } \\
\text { understood }\end{array}$ & $\begin{array}{l}\mathbf{2}= \\
\text { Not well } \\
\text { understood }\end{array}$ & $\begin{array}{l}\mathbf{1}= \\
\text { Not } \\
\text { understood } \\
\text { at all }\end{array}$ \\
\hline $\begin{array}{l}\text { Describe the function and } \\
\text { purpose of a structure. }\end{array}$ & & & & \\
\hline $\begin{array}{l}\text { Identify the different types of } \\
\text { structures and structural } \\
\text { elements }\end{array}$ & & & & \\
\hline $\begin{array}{l}\text { Identify the process involved } \\
\text { in the creation of a typical } \\
\text { civil engineering structure }\end{array}$ & & & & & \\
\hline $\begin{array}{l}\text { Identify and calculate the } \\
\text { different types of loads } \\
\text { acting on a structure or } \\
\text { structural element. e.g. Dead } \\
\text { loads, Live loads, Wind }\end{array}$ & & & & & \\
Loads & & & & & \\
\hline $\begin{array}{l}\text { Calculate applicable live } \\
\text { load reduction and reduced } \\
\text { live load on a structural } \\
\text { element }\end{array}$ & & & & & \\
\hline $\begin{array}{l}\text { Differentiate between } \\
\text { concentrated loads and } \\
\text { uniformly distributed loads. }\end{array}$ & & & & & \\
\hline $\begin{array}{l}\text { Work through the examples } \\
\text { in Text \#1 and complete the }\end{array}$ & & & & & \\
\hline
\end{tabular}

Proceedings of the 2005 American Society for Engineering Education Annual Conference \& Exposition Copyright (C) 2005, American Society for Engineering Education 


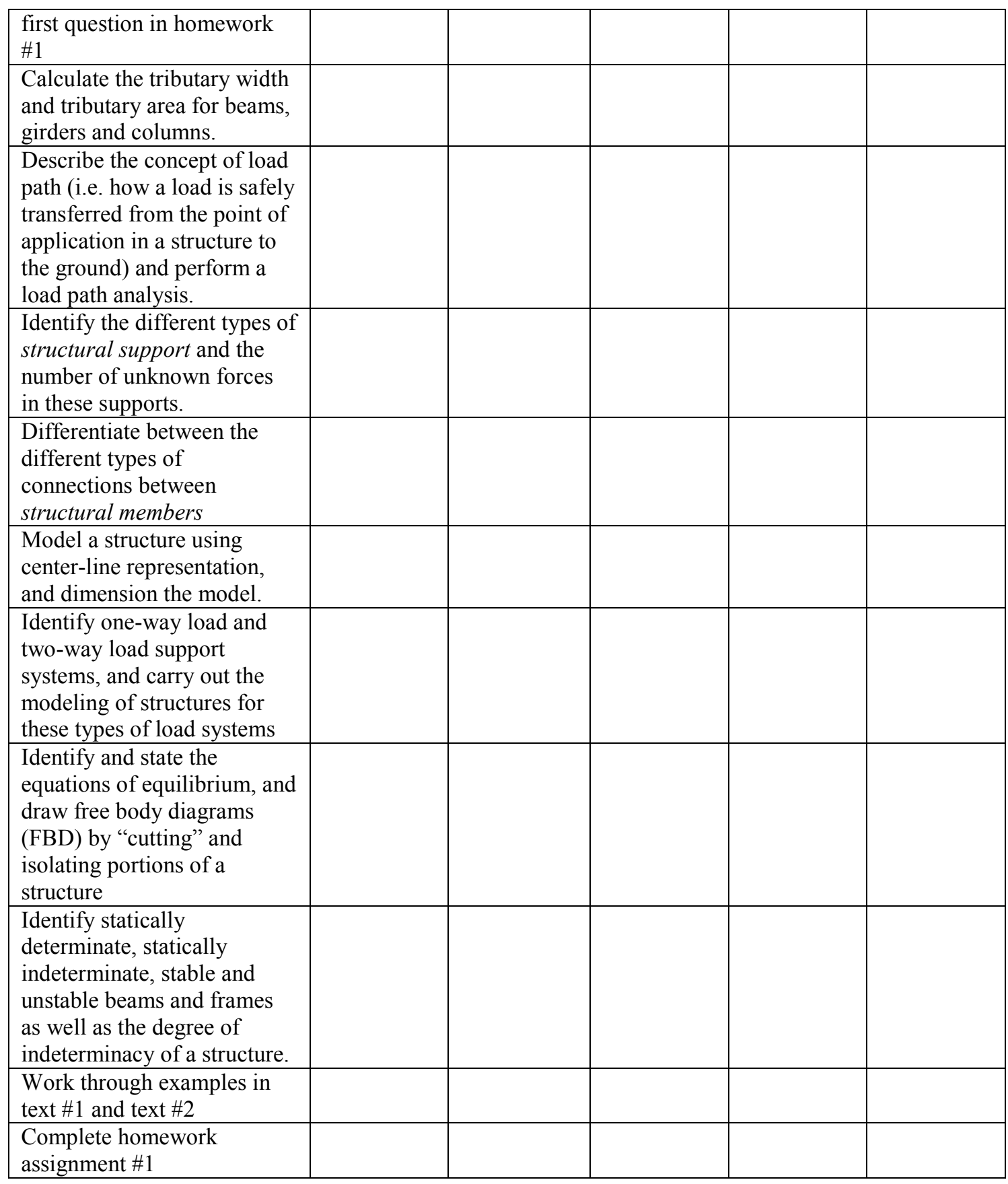

For this module, describe briefly what was most meaningful to you in terms of what you learned and what was unclear. 


\section{Module 8: OVERALL COURSE LEARNING OBJECTIVES or OUTCOMES}

After completing this course, you will be able to:

\begin{tabular}{|c|c|c|c|c|c|}
\hline & $\begin{array}{l}5= \\
\text { Very well } \\
\text { understood }\end{array}$ & $\begin{array}{l}4= \\
\text { Understood }\end{array}$ & $\begin{array}{l}3= \\
\text { Somewhat } \\
\text { understood }\end{array}$ & $\begin{array}{l}2= \\
\text { Not well } \\
\text { understood }\end{array}$ & $\begin{array}{l}1= \\
\text { Not } \\
\text { understood } \\
\text { at all }\end{array}$ \\
\hline $\begin{array}{l}\text { 1. Model structural } \\
\text { systems properly and } \\
\text { efficiently and determine } \\
\text { the loads acting on } \\
\text { structures and their } \\
\text { members. } \\
\text { a, b, f, } 10,11\end{array}$ & & & & & \\
\hline $\begin{array}{l}\text { 2. Analyze statically } \\
\text { determinate and } \\
\text { indeterminate structures to } \\
\text { determine the support } \\
\text { reactions and the shear } \\
\text { force, bending moment } \\
\text { and axial force in the } \\
\text { structural members. } \\
\text { a, b, f, } 10,11\end{array}$ & & & & & \\
\hline $\begin{array}{l}\text { 3. Interpret and verify the } \\
\text { results of computer-aided } \\
\text { analysis using } \\
\text { approximate and "exact" } \\
\text { hand calculation methods. } \\
\text { a, b, f, } 6,10\end{array}$ & & & & & \\
\hline $\begin{array}{l}\text { 4. Identify the gravity and } \\
\text { lateral load-resisting } \\
\text { systems used in structural } \\
\text { systems } \\
\text { a, b. f, } 10,11\end{array}$ & & & & & \\
\hline $\begin{array}{l}\text { 5. Conduct, analyze and } \\
\text { interpret experiments or } \\
\text { carry out research using } \\
\text { the internet and write a } \\
\text { report based on the } \\
\text { research } \\
c, g, h, i, k\end{array}$ & & & & & \\
\hline
\end{tabular}

\section{End-of-Term Survey Questions on Effectiveness of Course Modules}

1. How well did you reflect on the course topics (or intended learning outcomes) in the course modules before completing the module survey?

2. How did the module survey impact your learning in this course? 